\title{
SISTEM INFORMASI ADMINISTRASI KEPENDUDUKAN KELURAHAN REMBIGE BERBASIS WEB
}

\author{
Lulu Luciana Putri' ${ }^{1}$, Muhammad Fauzi Zulkarnaen², Hasyim asyari ${ }^{3}$ \\ Sistem Informasi, STMIK LOMBOK \\ Jln. Basuki Rahmat No 105 Praya Lombok Tengah 83511 \\ $\underline{\text { lucianaputri17@gmail.com }}^{1} \underline{\text { muhammadfauzizulkarnaen@gmail.com }}^{2}, \underline{\text { hasyimasyari25@gmail.com }}^{3}$
}

\begin{abstract}
Rapid technological advancements encourage every agency to keep abreast of technological developments and continue to improve its ability to manage data and information held to be more accurate and efficient. Processing population data is the responsibility of the district / city government, where the implementation begins with the kelurahan as the spearhead of population registration. In this service, it needs to be done quickly and precisely to get information.

The Office of the Village Head of Rembige still uses a manual system in population administration for which the author designed a web-based population administration information system.In making this Web Based Population Administration Information System the author uses the SDLC (Software Development Life Cycle) design method and uses MySQL for the database.

As for this information system, there will be an information menu on population administration and village profile.The results of this final project are based on population administration information systemsthe web.
\end{abstract}

keyword: web-based population administration information system

\begin{abstract}
Abstrak
Kemajuan teknologi yang sangat pesat mendorong setiap instansi untuk tetap mengikuti perkembangan teknologi dan terus meningkatkan kemampuan dalam mengelola data - data daninformasi yang dimiliki agar lebih akurat dan efisien. Pengolahan data penduduk merupakan tanggung jawab pemerintah kabupaten/kota, dimana pelaksanaannya di awali dari kelurahan selaku ujung tombak pendaftaran penduduk. Dalam pelayanan tersebut perlu dilakukan dengan cepat dan tepat untuk mendapatkan suatu informasi.

Kantor Lurah Rembige masih menggunakan sistem manual dalam administrasi kependudukan untuk itu penulis merancang sebuah sistem informasi administrasi kependudukan berbasis web.

Dalam pembuatan Sistem informasi Administrasi Kependudukan Berbasis Web ini penulis menggunakan metode perancangan SDLC (Software Development Life Cycle) serta menggunakan MySQL untuk database.

Adapun dalam sistem informasi ini nantinya akan terdapat menu informasi administrasi kependudukan,dan profile kelurahan.

Hasil dari Tugas akhir ini adalah berupa sistem informasi administrasi kependudukan berbasis web .

kata kunci : sistem informasi administrasi kependudukan berbasis web
\end{abstract}




\section{PENDAHULUAN}

Kemajuan teknologi yang sangat pesat mendorong setiap instansi untuk tetap mengikuti perkembangan teknologi dan terus meningkatkan kemampuan dalam mengelola data - data dan informasi yang dimiliki agar lebih akurat dan efisien. Untuk itu suatu instansi membutuhkan suatu system informasi yang mendukung kebutuhan instansi pemerintah guna menciptakan efisiensi dan efektifitas kerja, maupun meningkatkan pelayanan kepada masyarakat.

Sistem Informasi merupakan suatu system dalam suatu organisasi yang mempertemukan kebutuhan harian yang mendukung fungsi operasi organisasi yang bersifat manajerial pengolahan transaksi dengan kegiatan strategi dari suatu organisasi untuk dapat menyediakan kepada pihak luar tertentu dengan informasi yang diperlukan untuk mengambil keputusan. Seiring dengan perkembangan zaman, kemajuan teknologi pun berkembang sangat pesat. Hal ini dapat dilihat dari ketergantungan manusia akan informasi semakin bertambah sehingga kualitas informasi pun harus selalu di tingkatkan karena informasi mempunyai dampak yang cukup besar terhadap perkembangan lembaga atau instansi.

Pengolahan data penduduk merupakan tanggung jawab pemerintah kabupaten/kota,dimana pelaksanaannya diawali dari kelurahan selaku ujung tombak pendaftaran penduduk. Dalam pelayanan tersebut perlu dilakukan dengan cepat dan tepat untuk mendapatkan suatu informasi.

Pengolahan data pada kantor kelurahan Rembige masih dilakukan dalam bentuk pembukuan atau arsip - arsip, sehingga seringkali terjadi kesalahan bahkan ada arsip data yang hilang atau rusak karena terlalu banyak nya arsip yang ada.

Dari kegiatan tersebut menimbulkan permasalahan seperti tidak efisiennya waktu yang digunakan untuk memproses pelayanan kependudukan dalam pencarian data penduduk, proses administrasi pembuatan surat - surat pengantar( Kartu keluarga dan KTP),surat kelahiran,kematian dan surat pindah yang membutuhkan waktu yang cepat dan tepat.

Terkait dengan permasalahan yang telah dikemukakan pada latar belakang di atas, maka untuk memperlancar dan memudahkan proses administrasi kependudukan maka pada penelitian ini akan dibangun sistem informasi administrasi kependudukan di kelurahan Rembige berbasis web.

\section{TINJAUAN PUSTAKA}

Dalam penelitian Supardin dan Didin (2015) yang berudul "Aplikasi pengelolaan data penduduk di kantor kelurahan Margawati" [1]. Penelitian tersebut bertujuan merancang aplikasi data kependudukan yang mencakup data kelahiran,kematian, serta laporan kependudukan lainnya dengan hasil adanya sebuah aplikasi yang dapat mengelola data penduduk secara khusus.

Menurut Jananto dan Arief (2013) dalam penelitiannya yang berudul "Sistem Informasi Administrasi kependudukan pada kelurahan Sampangan Bandung " [2]. Penelitian tersebut bertujuan merancang sebuah sistem informasi administrasi kependudukan agar dapat melakukan pekerjaan secara cepat, dan tepat sehingga pada akhirnya lebih mudah dan lebih efisien dalam mendapatkan informasi kependudukan. Hasil dari Aplikasi Sistem Informasi Kependudukan ini menghasilkan beberapa laporan yaitu laporan data penduduk, laporan data masuk, laporan data pindah, laporan kelahiran dan laporan kematian.

Menurut Noviyanto dan Fiftin (2014) dalam jurnalnya yang berudul "Implementasi sistem informasi kependudukan desa (SIKADES) untuk kemudahan layanan adiministrasi desa berbasis web mobile [3"]. Penelitian tersebut bertujuan untuk membangun sebuah layanan public berbasis web mobile agar Masyarakat dapat mengakses data menggunakan sistem melalui berbagai perangkat yang terhubung dengan internet (handphone, komputer dan perangkat komunikasi lainnya). Hasil dari penelitian ini yaitu Sistem telah di uji coba oleh programmer maupun pengguna menggunakan perangkat mobile dan personal Computer (PC). Berdasarkan pengujian tersebut, sistem dapat digunakan dan dioptimalkan untuk pengelolaan data administrasi kependudukan.

Dalam jurnal Adin dan andra (2013) yang berjudul Pengembangan sistem terdistribusi untuk sistem informasi administrasi kependudukan dengan integrasi teknologi RMI dan web service [4]. Penelitian ini bertujuan untuk mengatasi pembagian kinerja sistem dan web service untuk melakukan ekspansi data, dan tidak bersifat menggantikan sistem informasi yang telah ada, namun berfungsi sebagai pemodelan sistem informasi dengan arsitektur sistem terdistribusi. Hasil dari 
penelitian ini yaitu sistem informasi yang dibangun sudah memiliki proteksi transparansi terhadap sumber data yang dimiliki serta sudah memenuhi standar operasional.

Selain itu, menurut Juniarta dan danang (2013) dalam penelitiannya yang berjudul "Perancangan sistem informasi pelaporan monografi berbasis web (studi kasus pada kantor kecamatan Semarang Utara)" [5]. Penelitian ini bertujuan agar dibangun sebuah aplikasi sistem informasi yang dapat membantu pembuatan laporan monografi berbasis web. Hasil dari penelitian yaitu sistem informasi pelaporan ini meningkatkan kinerja pelaporan pegawai, sehingga meningkatkan keunggulan pelayanan kecamatan Semarang Utara kepada mayarakat.

\section{METODOLOGI}

\subsection{Metodologi Penelitian}

Untuk mengidentifikasi masalah harus dilakukan analisis terhadap kinerja, informasi, ekonomi, keamanan aplikasi, efisiensi dan pelayanan-pelayanan. Panduan ini dikenal dengan Analisis PIECES ( Performance, information, economics, control, efficiency dan service).

\subsection{Metode Perancangan Software Development Life Cycle ( SDLC).}

Metode Perancangan Sistem adalah sebuah cara atau metode yang bertujuan untuk melakukan analisa pengembangan dan perancangan suatu sistem agar sistem tersebut dapat memenuhi kebutuhan. Metode yang digunakan untuk merancang sistem yang akan dibuat yaitu Software Development Life Cycle ( $S D L C$ ). Proses yang terdiri dari serangkaian kegiatan yang direncanakan untuk mengembangkan atau mengubah produk perangkat lunak. SDLC digunakan oleh industri perangkat lunak (software) untuk merancang, mengembangkan dan menguji serta bertujuan untuk menghasilkan perangkat lunak berkualitas tinggi yang memenuhi harapan User/Customer dalam waktu dan perkiraan biaya yang telah ditentukan. Berikut adalah gambar dari tahapan $S D L C$ :

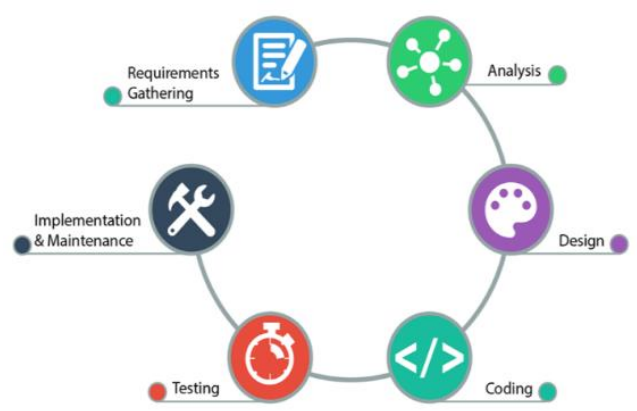

Gambar2.1 $S D L C$

\section{HASIL DAN PEMBAHASAN}

Untuk mengidentifikasi masalah, maka perlu melakukan analisis terhadap kinerja, infomasi, ekonomi, control, efisiensi dan pelayanan. Panduan ini dikenal dengan PIECES Analysis (Performance, Information, Economy, Control, Efficiency, Services). Dari analisa ini peneliti mendapatkan beberapa masalah dan akhirnya menemukan masalah utama. Dari beberapa solusi yang ditawarkan, peneliti memilih untuk membangun system informasi administrasi kependudukan di kelurahan Rembige berbasis web,yang dapat menyajikan informasi secara tepat, cepat dan akurat.

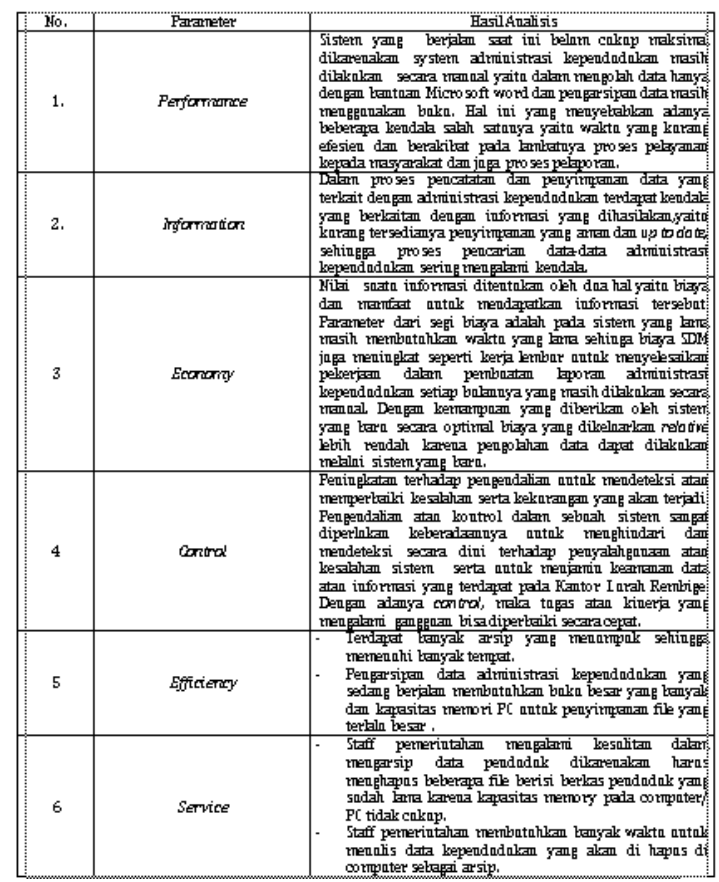




\subsection{Diagram Konteks sistem yang diusulkan}

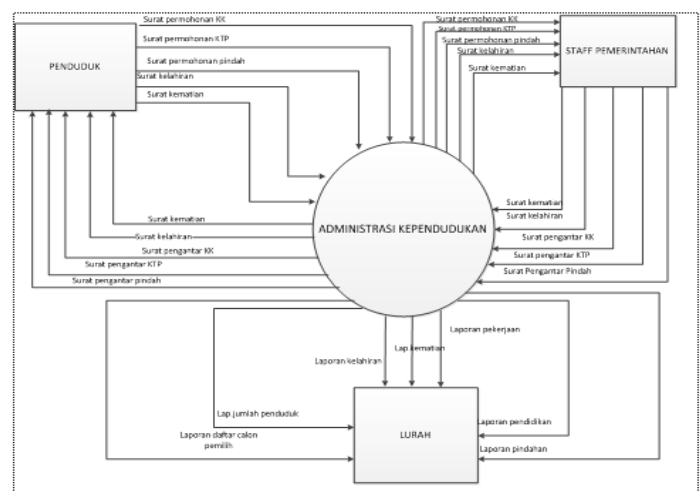

Gambar 4.1 Diagram konteks sistem yang diusulkan menjelaskan bahwa :

1. Seluruh permohonan blangko yang di ajukan oleh penduduk atau pemohon akan di proses di sistem informasi administrasi kependudukan, lalu hasil dari sistem tersebut dicetak untuk diserahkan kepada penduduk atau pemohon.

2. Staff pemerintahan memiliki akses untuk melogin sistem informasi administrasi tersebut untuk menginput data kependudukan atau memproses blangko permohonan oleh pemohonan.

3. Lurah dapat mengakses atau melogin sistem administrasi tersebut dan dapat memproses informasi berupa laporan kependudukan, laporan kelahiran, dan laporan pekerjaan.

\subsection{Struktur Menu}

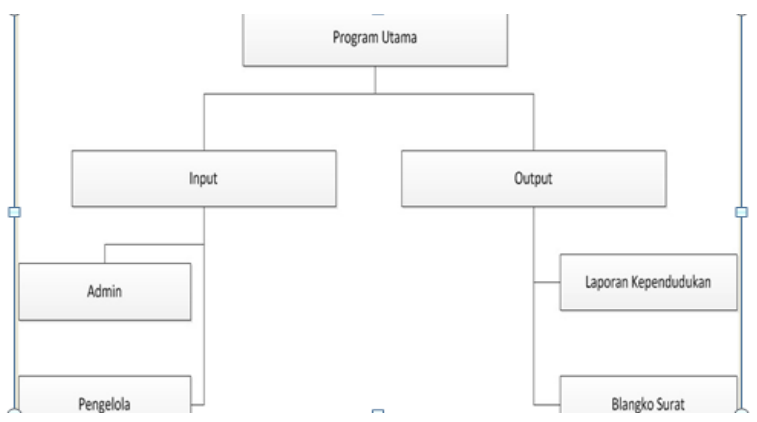

Gambar 4.2 struktur menu menjelaskan bahwa menu pada program menu utama merupakan menu awal dalam sistem ini, dimana terdapat dua sub menu yaitu menu input dan menu output. Pada menu input terdapat dua pilihan menu yaitu admin dan pengelola. Pada sistem ini, admin dan pengelola memiliki kuasa penuh untuk mengakses langsung sistem ini, serta biasmengelola sistem ini secara keseluruhan mulai dari mengedit, memasukan data, menghapus data sampai membuat laporan kependudukan. Pada menu output terdapat menu laporan kependudukan dan blangko surat, dimana kedua menu ini merupakan hasil atau tampilan yang diperolah dari proses menu input yang dilakukan oleh admin dan pengelolaan.

\subsection{Interface}

\subsubsection{Halaman Login}

Halaman login merupakan halaman yang akan ditampilkan oleh aplikasi ketika user atau pengguna menginstall atau membuka aplikasi untuk pertama kali. Halaman login digunakan sebagai proses authentification atau proses pengecekan.

Akun sebagai syarat untuk dapat masuk kehalaman utama aplikasi. Proses authentificationdilakukan dengan cara memasukan inputan berupa username dan password dari masing - masing pengguna. Pengguna dapat masuk menggunakan akun yang sudah terdaftar di database sistem. Hasil implementasi untuk halaman login dari aplikasi dapat dilihat pada Gambar 4.1 dibawah ini.

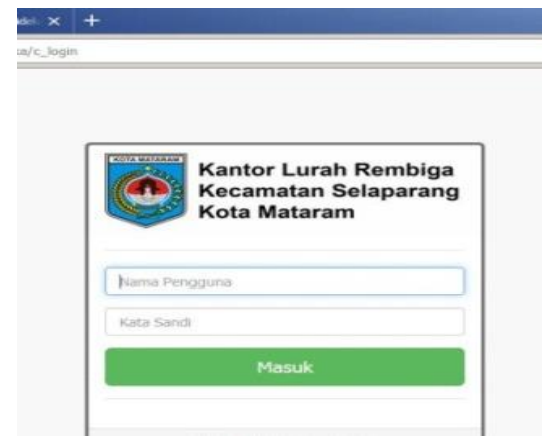

Gambar 4.3 Halaman login

\subsection{Halaman Utama}

Halaman utama merupakan halaman yang akan ditampilkan oleh aplikasi ketika user sudah berhasil login. Padahalaman utama terdapat tampilan menu utama dan beberapa pilihan menu lainnya yang terdiri dari beranda, profilkelurahan/desa, berita, regulasi 


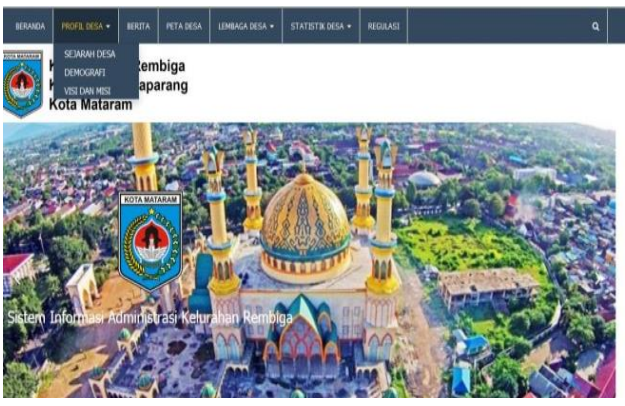

Gambar 4.4. Halaman utama

\subsection{Halaman administrator}

Administrator adalah orang yang bertanggung jawab mengelola,menjalankan dan merawat program aplikasi. Administrator bertanggung jawab dalam setia transaksi yang dilakukan, misalnya menambah, mengurangi, menghapus dan mengganti rekaman - rekaman yang ada dalam database. Untuk dapat menjaga agar data tetap konsisten,maka tidak setiap orang dapat masuk kedalam basis data maka diperlukan user authentification. Dimana administrator mempunyai user id dan password untuk masuk kedalam program.

Menu administrator pada aplikasi ini digunakan untuk mengakses halaman halaman lain pada aplikasi.

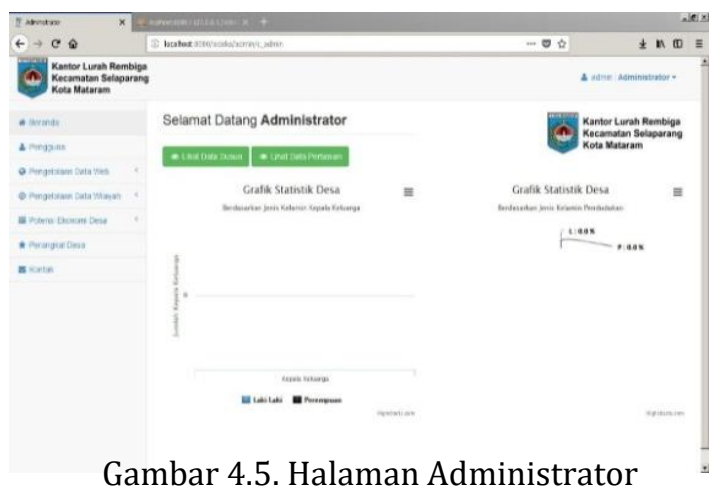

\subsection{Black box texting}

Tabel 4.1 Evaluasi Pengujian Sistem
\begin{tabular}{|c|l|c|c|}
\hline No & \multicolumn{1}{|c|}{ AlurPengujian } & Hasil & Score \\
\hline 1 & $\begin{array}{l}\text { Aplikasi menampilkan dialog pemberitahuan } \\
\text { ketika status pengguna adalah offline }\end{array}$ & Belum Berhasil & 0 \\
\hline 2 & $\begin{array}{l}\text { Aplikasi menampilkan menu utama pada web } \\
\text { saat status pengguna adalah offline }\end{array}$ & Berhasil & 1 \\
\hline 3 & $\begin{array}{l}\text { Aplikasi menampilkan sistem informasi } \\
\text { administrasi kependudukan sesuai lokasi } \\
\text { online }\end{array}$ & Berhasil & 1 \\
\hline 4 & $\begin{array}{l}\text { Aplikasi menampilkan menu login dan dapat } \\
\text { di akses setelah memasukan id dan pasword }\end{array}$ & Berhasil & 1 \\
\hline 5 & $\begin{array}{l}\text { Aplikasi menampilkan informasidan data } \\
\text { kependudukan }\end{array}$ & Berhasil & 1 \\
\hline & \multicolumn{1}{|c|}{ Total } & $\begin{array}{c}4 / 5 \times 100 \% \\
=80 \%\end{array}$ \\
\hline
\end{tabular}

Gambar 4.6 Balckbox testing

Adapun hasil dari proses uji coba keseluruhan modul aplikasi yang menggunakan metode Black Box Testing yakni melakukan proses uji coba terhadap fungsi utama dari aplikasi. Kesimpulan yang dapat diambil yaitu aplikasi layak untuk digunakan.

\section{KESIMPULAN DAN SARAN 5.1 Kesimpulan}

Adapun kesimpulan terhadap penelitian yang dilakukan mulai dari proses perencanaan sampai dengan proses implementasi dan testing yaitu mampu menghasilkan sebuah aplikasi yang dapat digunakan untuk keperluan administrasi kelurahan Rembige berupa keperluan surat menyurat, laporan kependudukan, dan data penduduk.

\subsection{Saran}

Diharapkan aplikasi ini bermanfaat bagi satuan kerja perangkat kelurahan dalam mengelola data dikelurahan dan kedepannya dapat dikembangkan untuk lebih mempermudah dalam proses administrasi kependudukan dan akses website. Pada pengembangan selanjutnya yang perlu diperhatikan adalah : Semua menu yang ditampilkan di sistem harus dilengkapi dengan data sesuai menu tersebut. Memperbaharui data secara berkala

\section{DAFTAR PUSTAKA}

[1] D. Supardin and Bunyamin, "Aplikasi pengelolaan data penduduk di kantor kelurahan margawati," Informatika, vol. 12, pp. 1-7, 2015.

[2] S. A. Jai, D. Setyawan, I. Adiwidjaja, P. Studi, I. Administrasi, and U. T. Tunggadewi, "Sistem Informasi Administrasi Kependudukan," vol. 5, no. 1, pp. 34-38, 2016.

[3] F. Noviyanto, T. Setiyadi, and I. Wahyuningsih, "JURNAL INFORMATIKA Vol. 8, No. 1, Januari 2014," Implementasi Sikades (Sistem Inf. Kependud. Desa) Untuk Kemudahan Layanan Adm. Desa Berbas. Web Mob., vol. 8, no. 1, pp. 858-869, 2014.

[4] Y. R. Beeh, "Jurnal Aiti diterbitkan oleh Fakultas Teknologi Informasi," vol. 9, no. 1, 2012.

[5] D. Juniarta, Q. Shinta, and F. Nurhakim, "Perancangan Sistem Informasi Pelaporan Monografi Berbasis Web," Speed, vol. 5, no. 2, pp. 21-30, 2013.

[6] Gani, A., \& Baye, W. (2018). Sistem Informasi Praktek Kerja Industri Pada SMK Islam Sirajul Huda Paok Dandak. Jurnal 
http://e-journal.stmiklombok.ac.id/index.php/misi

Manajemen Informatika dan Sistem Informasi, 1(1), 52-56.

[7] Y. Arianti dan M. Ashari, "Sistem Informasi Penjualan Pada Toko Al-Idan Variasi Motor Kelurahan Karang Baru Kecamatan Mataram," Jurnal Manajemen Informatika dan Sistem Informasi (MISI), vol. 1, no. 1, pp. 46-51, Januari 2018.

[8] H. A. Fatta, Analisis dan Perancangan Sistem Informasi, Yogyakarta: Andi Offset, 2007.

[9] A.-B. b. Ladjamudin, Analisis dan Desain Sistem Informasi, Yogyakarta: Graha Ilmu, 2005.
[10] A. Nugroho, Analisis dan Perancangan Sistem Informasi dengan Metodologi Berorientasi Object, Bandung: Informatika, 2005.

[11] M. T. A. Zaen dan B. S. Mardiani, "Sistem Informasi Pengelolaan Dana Bantuan Operasionl Sekolah (BOS) SMK AL-Hasanain Beraim Berbasi PHP dan MySQL," Jurnal Manajemen Informasi dan Sistem Informasi (MISI), vol. 1, no. 2, pp. 62-68, Juni 2018. 